\title{
Metastatic squamous cell carcinoma of the hand and review of the literature
}

\author{
FIt Lt SJ Foley \\ FRCS, RAF \\ Senior House Officer
}

\author{
FIt Lt A Pay \\ MBBS, RAF \\ Senior House Officer
}

Cade Oncology Unit, Princess Mary's Royal Air Force Hospital, Halton, Aylesbury, Bucks

Wg Cdr GP Howell

FRCS(Ed), RAF

Consultant Surgeon

Princess Alexandra Hospital, RAF Wroughton, Swindon, Wilts SN4 OQJ

\section{$S$ Holt}

FRCS

Consultant Surgeon

Llanelli Hospital, Dyfed SA14 8QF

SUMMARY: New cases of cancer amongst medical workers arising as a result of X-ray exposure are now rare. V record a case of a dentist who presented 11 years ago with a radiation induced squamous cell carcinoma of the rin finger of his left hand with massive axillary lymphadenopathy. Repeated exposure of his hands to diagnostic denfil irradiation in his surgery had lead 16 years previously to a troublesome radiodermatitis which had betn mistakenly diagnosed and had itself been treated with radiotherapy without effect.

Management by amputation of the distal phalanx of the ring finger, debulking of the axillary lymphadenopathy with adjunctive radiotherapy to the axilla and chemotherapy, have been successful in achieving a prolonged disease free interval and satisfactory hand function.

\section{Introduction}

Professor Wilhelm Conrad Roentgen discovered X-rays on the 8th November 1895 at the Institute of Physics in the University of Wurzburg in Bavaria. Within 3 months he had obtained a radiograph of the hand in which the bony skeleton could be clearly seen against a soft tissue background.

Later in 1896 Daniel (1) reported the first cases of acute radiodermatitis and evidence rapidly accumulated of other deleterious effects from X-rays including pigmentation, telangiectasis, fibrosis, scarring, alopecia and ulceration. Six years later, Frubein (2) published the first case of radiation induced cancer in a 33 year old technician who,after working for 4 years demonstrating roentgen tubes, developed an epithelioma of the hand with regional lymph node metastases. Other cases followed amongst pioneering radiation workers and several decades later amongst patients exposed to therapeutic irradiation for a wide range of conditions. Many cases of squamous cell and basal cell skin cancers, sarcomas, thyroid cancers and leukaemias were reported (3) generally with latent periods between exposure and development of $7-25$ years.

\section{Case Reports}

A 52 year old practising dentist was referred in October 1986 with chronic radiodermatitis of both hands, recent: onset of ulceration of the pulp of the terminal phalanx of the left ring finger (Fig 1) and massive lymphadenopathy of the left axilla.

A full history revealed that since qualifying in 1957 , he had adopted the habit of holding dental X-ray films in hisळ patients' mouths during X-ray exposure. This hadF occurred about 15 times in a working day during $1957:$ increasing to 40 times daily in busy clinics during 1973.

In 1970 he developed a troublesome dermatitis of the hands that failed to respond to topical medications, including steroids. A diagnosis of chronic lichenified? eczema was made and treatment with radiotherapy carried out, but without therapeutic response. It was not untip 1973 that the relationship between radiation exposure anch the "dermatitis" was identified and the dentist adopted" stringent precautions in his day to day practice.

At follow up, small moist ulcers which developed were्ట treated successfully with liquid nitrogen applications Hand function became slightly impaired when stiffness of 
the fingers developed as a consequence of radiation fibrosis affecting the soft tissues. In 1986, thirteen years after his last X-ray exposure, an ulcer developed on the terminal pulp of the left ring finger which failed to heal and was followed by the onset of massive axillary lymphadenopathy. A second smaller ulcer was identified on the right middle finger.

Full examination and staging investigations failed to reveal any other metastases. At operation, a frozen section of the ulcer on the left ring finger was performed and this confirmed squamous cell carcinoma. An amputation of the terminal phalanx was carried out and the massive left axillary lymphadenopathy was debulked. A complete clearance however was not technically feasible,

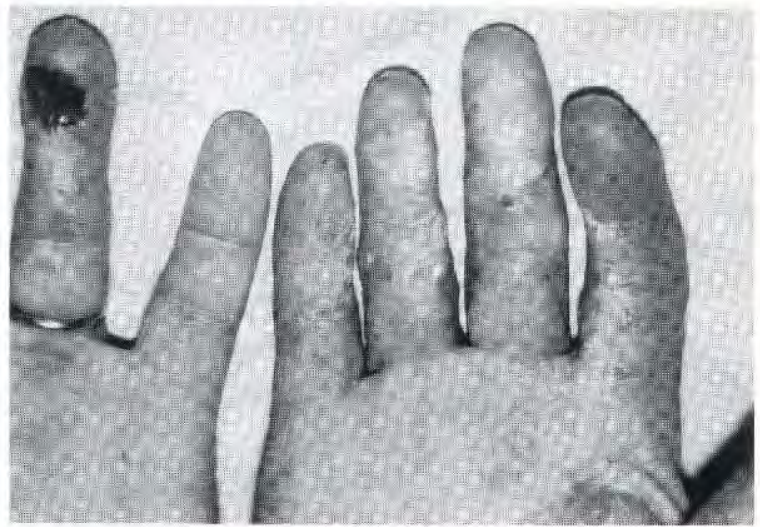

Fig 1: Radiodermatitis and Squamous Cell Carcinoma in the hands of a dentist.

Surgery as a sole treatment modality was clearly inadequate and systemic chemotherapy (Bleomycin and Cisplatin) was given on two occasions at three week intervals following operation. In addition, the left axilla and supra clavicular fossa were treated with external beam radiotherapy - 60 Gys in 30 fractions over 47 days. The small ulcer on the right middle finger healed promptly following application of 5-Fluorouracil ointment.

At most recent review 6 years after completing treatment our patient remains well with no sign of local or distant recurrence of his squamous cell carcinoma. Chronic radiodermatitis persists with intermittent superficial ulceration which responds to 5-Fluorouracil ointment (Fig 2). Hand function is a little impaired but our patient has been able to continue with his professional duties.

\section{Discussion}

The exact relationship between radiation dose and effect is not clear but with regard to skin irradiation, increased exposure, even in multiple small fractionated doses without immediate reaction, leads to an increased probability of developing radiodermatitis and cancer.

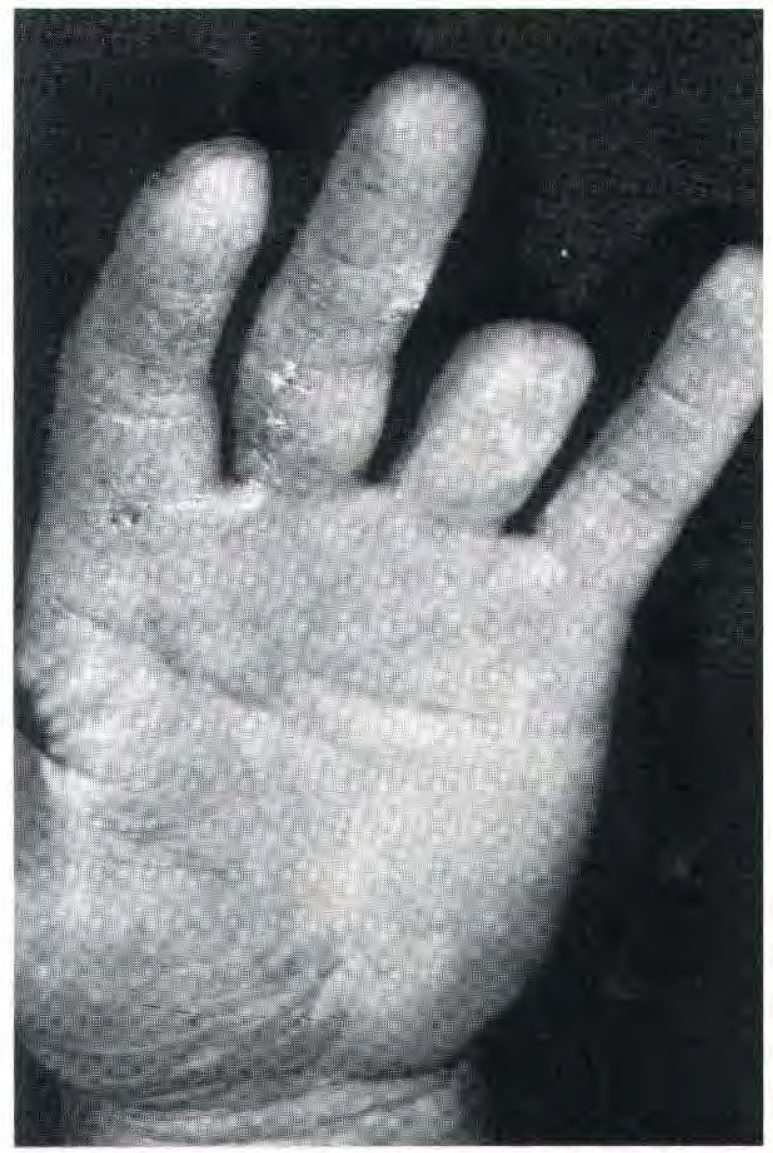

Fig 2: Radiodermatitis and Squamous Cell Carcinoma in the hands of a dentist.

Though skin cancer occasionally develops without preexisting clinical signs of radiation damage, most cases arise within areas of chronic radiodermatitis. It seems that most adults can accumulate a superficial dose confined to the skin of 10 Grays without untoward results (4). The potential of radiodermatitis is likewise variable and in a few cases the condition may be severe with ulceration and necrosis yet continue for many years before malignant transformation occurs.

If radiodermatitis persists long enough, 50 years in some, cancer will be an inevitable result (5).

$\mathrm{X}$-rays, once used widely for treating some common dermatological conditions and in cosmesis, are now restricted to well defined roles in the dermatological management of skin cancers and very occasionally in resistant benign dermatoses. Large and complicated cancers of the eye lid, nose and lip respond well to properly administered radiotherapy with results comparable to and sometimes better, both therapeutically and cosmetically, than refined surgery. Cutaneous lymphomas are often highly radiosensitive and respond to low doses of conventional radiotherapy. 
Indications for radiotherapy in benign skin diseases have been narrowed to a very few dermatoses that do not respond to other modes of treatment and should only be considered where active treatment is essential to the well being of the patient. Limitation of the total fractionated dose over a lifetime to 10 Grays of X-rays, 50 Grays for the minimally penetrating Grenz rays and the application of meticulous radiation protection measures are essential (6). Indications include resistant or recurrent keloids, chronic lichenified eczema, lichen simplex and a rare resistant cases of psoriasis.

It is only possible to speculate the accumulated dose of radiation acquired by our patient from diagnostic dental $\mathrm{X}$-ray exposure. Assuming a possible dose to the skin of his fingers of 4-6.5 mGy per dental film, a Tissue Weighting Factor for skin of 0.01 , and assuming that he may have performed 15 films at least per working day in 1957 and up to 40 in 1973, total exposure to his hands may have been in the order of 14 Grays. An additional 12 Grays of "therapeutic" radiotherapy for his "dermatitis" were accumulated in 1970.

\section{Conclusions}

This case demonstrates that new cases of radiation induced skin injury in the medical and dental profession may still occur. Dermatologists should view their medical colleagues with suspicion and take a full occupational history when they present with a dermatitis that proves resistant to usual remedies. The education of all radiation users, particularly those on the periphery of diagnostic radiology, is vital and this case highlights the need for recent charges in legislation (7).
The benefit of combined modality therapy for metastatic squamous cell carcinoma, involving surgical debulking of lymph node metastases supplemented by radiotherapy and chemotherapy is well illustrated in this case (8).

\section{Acknowledgements:}

The authors are grateful to Air Marshall RTB Jones? RAF (Rtd), previously Senior Consultant to the Royal Air Force, for his advice and the use of his clinical $\overrightarrow{\mathbb{D}}$ photographs, and to Gp Capt M Mahoney, Head of the Cade Unit, for permission to publish this case.

\section{REFERENCES}

1. Daniel J. The X Rays. New Science 1896; 3:562.

2. FRIEBEN EA. Cancroid des rechten handrueckens nach langdauernder einwirkung Von Roentgenstrahlen. Fortsschr Roentgenstr 1902; 6:106.

3. CADE S. Radiation induced cancer in man. $\mathrm{Br} J$ Radiol 1957; 393-402.

4. ROWELL N. Adverse effects of superficial X-ray therapy and recommendations for safe use in benigg dermatoses. J Dermatol Surg Oncol 1978; 4:630-63థ

5. HoOD IC, YOUNG JEM. Late sequalae of superfic irratiation. Head Neck surg 1984; 7:65-72.

6. Goldschmidt H. Dermatologic Radiotherapy 1989. Arch Dermatol 1981; 117:685-688.

7. Ionising Radiations Regulations 1985 and 1988.

8. NALTENIUS HW. Manual of Oncology 1981:1162. 